\title{
Up-regulation of PCSK9 gene expression and diminished level of LDL-receptor in rat liver as a potential cause of post-lipectomy hypercholesterolemia
}

\author{
Agnieszka Dettlaff-Pokora ${ }^{1} \cdot$ Elzbieta Sucajtys-Szulc $^{2} \cdot$ Tomasz Sledzinski $^{3}$
}

Received: 7 July 2018 / Accepted: 23 November 2018 / Published online: 27 November 2018

(c) The Author(s) 2018

\begin{abstract}
Studies designed to examine effects of fat mass reduction (including lipodystrophy and lipectomy) on human serum total and LDL-cholesterol concentrations are inconsistent. The purpose of this study was to examine effect of partial lipectomy in rats (as an experimental model of fat mass reduction in humans) on (1) circulating total cholesterol, LDL-cholesterol + VLDLcholesterol and HDL-cholesterol concentrations, and (2) factors which may affect serum cholesterol concentrations such as: (a) liver LDL-receptor level, (b) expression of liver PCSK9 and (c) circulating PCSK9 concentration. Reduction of rat adipose tissue mass resulted in an increase in circulating total and LDL + VLDL-cholesterol concentrations, which was associated with (a) decrease in liver LDL-R level, (b) increase in liver PCSK9 expression, and (c) increase in circulating PCSK9 concentration as compared with sham controls. These changes were accompanied by elevated liver HNF1 $\alpha$ (and HNF4 $\alpha$ ) mRNA levels. Silencing HNF1 $\alpha$ in HepG2 cells by siRNA led to decrease in PCSK9 mRNA levels. This suggests that overexpression of HNF1 $\alpha$ gene in liver of lipectomized rats can lead to overproduction of PCSK9. In conclusion, up-regulation of PCSK9, due to overexpression of HNF1 $\alpha$ gene in liver of lipectomized rats and subsequently increase in circulating PCSK9 concentration lead to decrease in liver LDL-R level. This may contribute, at least in part, to an increase in the concentration of circulating cholesterol in rats with reduced fat mass. These findings provide a possible explanation for the molecular mechanism of hypercholesterolemia observed sometimes after reduction of fat mass in human.
\end{abstract}

Keywords HNF1 $\alpha \cdot$ PCSK9 $\cdot$ LDL-R $\cdot$ Hypercholesterolemia $\cdot$ Lipectomy

\section{Introduction}

Liposuction is popular esthetic surgery to remove significant amount of subcutaneous adipose tissue within a short period of time, recommended by the American Academy of Cosmetic Surgery [1]. However, the metabolic consequences of liposuction or abdominal lipectomy, especially changes in serum lipids concentrations, are still controversial

Agnieszka Dettlaff-Pokora

agnieszka_dettlaff-pokora@gumed.edu.pl

1 Department of Biochemistry, Faculty of Medicine, Medical University of Gdansk, Debinki 1, 80-211 Gdansk, Poland

2 Department of Nephrology, Transplantology and Internal Medicine, Faculty of Medicine, Medical University of Gdansk, ul. Debinki 7, 80-211 Gdansk, Poland

3 Department of Pharmaceutical Biochemistry, Faculty of Pharmacy, Medical University of Gdansk, Debinki 1, 80-211 Gdansk, Poland
[2]. The results of previous studies performed in humans have shown: (a) no change [3-7], (b) decrease [8-11], or (c) increase [12] in one or few cardiovascular risk factors including dyslipidemia.

Conflicting results regarding dyslipidemia characterized by: (a) elevated serum total and LDL-cholesterol, (b) elevated serum TAGs and (c) reduction of serum HDL-cholesterol in patients with lipodystrophy were also observed [13-15]. Moreover, individuals with lipodystrophy are at significantly increased risk of atherosclerosis and its consequences like heart disease [16]. Also the results concerning the effect of liposuction on serum cholesterol levels are inconsistent [3-11]. Thus, further studies are needed to clarify the effect of fat loss on lipid metabolism at the molecular level. It seems that, the lipectomy model offers some insight into how fat mass reduction may affect hypercholesterolemia sometimes observed in individuals after weight loss.

Lipectomy performed in obese rat (obesity induced by animal feeding with high fat and high cholesterol diet) had 
no significant effect on serum concentration of total, LDLand HDL- cholesterol, but caused higher concentrations of TAGs [17]. Recently we have shown, that partial surgical removal of white adipose tissue in rats is associated with the parallel up-regulation of liver HNF1 $\alpha$ (and HNF4 $\alpha$ ) and genes encoding proteins involved in synthesis, assembly and secretion of TAGs (including ApoB-100 and microsomal triglyceride transfer protein-MTP) as well as serum TAGs concentration [18]. Up-regulation of gene encoding $\mathrm{HNF} 4 \alpha$ was also observed by Ling et al. [17] in lipectomized rats as compared to control animals. Since VLDL and LDL contain ApoB-100 and plasma ApoB-100 concentrations correlates with plasma LDL-cholesterol concentrations [19], one can suppose that increased apoB-100 synthesis and its plasma concentration is also associated with elevated cholesterol concentrations in lipectomized rats.

It is well documented that HNF1 $\alpha$ and HNF $4 \alpha$ contribute to enhanced expression of genes encoding: (a) ApoB$100[20,21]$ and (b) proprotein convertase subtilisin/kexin 9 (PCSK9) in liver, what is associated with an increase in serum PCSK9 concentrations and consequently with elevated serum cholesterol concentration [22-26]. PCSK9 plays a pivotal role in posttranslational regulation of LDL-R level and subsequently regulation of serum LDL-cholesterol concentration [27]. Several papers reported a positive correlation between concentrations of PCSK9 and LDL-cholesterol in circulation [28-31]. Loss-of-function mutations in human HNF $4 \alpha$ cause maturity-onset diabetes of the young type 1 (MODY1) and decrease of plasma cholesterol concentrations [32-35]. Moreover HNF4 $\alpha$ is an upstream activator of HNF1 $\alpha$ [36], which in turn affects the expression of genes involved in cholesterol and other lipids metabolism [37, 38]. Thus, reciprocal relationship between HNF $1 \alpha$ and HNF $4 \alpha$ $[39,40]$ may play important role in regulation of serum cholesterol concentrations.

The aim of this study was to verify if an increase in HNF $1 \alpha$ and HNF $4 \alpha$ gene expression in the liver is associated with activation of PCSK9 production, which through degradation of LDL-R may lead to increase in serum cholesterol concentrations in lipectomized rats.

\section{Methods}

\section{Animals and surgeries}

The rats were fed ad libitum with standard commercial chow (Laborfed, Poland). Briefly, 12-week-old male Wistar rats were randomly divided into two groups: (1) lipectomized rats $(n=10)$ subjected to resection of epidydymal and retroperitoneal WAT, and (2) controls $(n=10)$ that underwent sham surgery: anesthesia and incision of the skin and muscles without the removal of WAT. After 30 days, the lipectomized rats were anesthetized again with subsequent removal of subcutaneous WAT, and the controls were subjected to another sham surgery. Mean weight of WAT removed from the lipectomized rats was $7.7 \pm 0.6 \mathrm{~g}$ $(3.8 \pm 0.3 \mathrm{~g}, 2.0 \pm 0.4 \mathrm{~g}$, and $1.9 \pm 0.4 \mathrm{~g}$ for inguinal, epidydymal, and retroperitoneal WAT, respectively). The lipectomy was performed as the two-step procedure in order to reduce perioperative mortality and the surgeries were conducted carefully to avoid bleeding. All animals received human care in compliance with the guidelines for the protection of animals used for scientific purposes (Directive, 2010/63 EU, Decision, 2012/707/UE and RD 53/2013). All the procedures involving animals and their care were approved by the Institutional Ethics Committee. The rats were anesthetized and killed by decapitation (between 8:00 a.m. and 10:00 a.m.) after 90 days from the first surgery. Blood samples from the carotid artery were collected to the tubes without anticoagulant, centrifuged at $3000 \times g$ for $15 \mathrm{~min}$ at $4{ }^{\circ} \mathrm{C}$, and the serum was stored at $-80^{\circ} \mathrm{C}$. At the end of experiments the liver fragments were obtained, immediately frozen in liquid nitrogen and stored at $-80^{\circ} \mathrm{C}$ until analysis. Epidydymal, retroperitoneal and inguinal WAT from the controls, as well as the residual WAT from the lipectomized animals, were removed and immediately weighted.

\section{Serum PCSK9 determination}

Commercial ELISA kit was used to estimate PCSK9 in rat serum (CSB-EL017647RA, CUSABIO). Assay was performed according to the manufacturer instruction.

\section{Serum cholesterol concentrations assays}

Serum total cholesterol concentration was determined using a routine method, at the Central Clinical Laboratory, Medical University of Gdansk. Serum HDL- and LDL- + VLDLcholesterol was measured using HDL and LDL/VLDL Quantitation Kit (Sigma, MAK045). Serum samples were mixed with Precipitation Buffer (2:1), incubated for $10 \mathrm{~min}$ at room temperature and centrifuged at $2000 \times g$ for $10 \mathrm{~min}$. The precipitate contains LDL/VLDL and the supernatant HDL fractions of cholesterol. Sediment was collected and centrifuged again to remove all remaining trace HDL supernatant. Precipitate was resuspended in Phosphate Buffered Saline (PBS) and the rest of the experiment was performed according to the manufacturer instruction.

\section{Liver cholesterol assays}

Total liver cholesterol, cholesterol esters and free cholesterol were measured using Cholesterol Quantitation Kit (Sigma, MAK043). In brief: $10 \mathrm{mg}$ of liver tissue was extracted 
with $200 \mu \mathrm{L}$ of chloroform:isopropanol:IGEPAL CA-630 (7:11:0.1) (Sigma, I8896) in a microhomogenizer. Samples were centrifuged for $10 \mathrm{~min}$ at $13,000 \times g$ in order to remove insoluble material. Organic phase was transferred to a new tube and dried at $50{ }^{\circ} \mathrm{C}$ and further placed under vacuum for $30 \mathrm{~min}$ to remove all organic solvents. Dried lipids were resolved in $200 \mu \mathrm{L}$ of the Cholesterol Assay Buffer, vortexed and sonicated until mixture became homogenous. Cholesterol was measured using fluorometric method ( $\lambda$ ex $=535$ / $\lambda \mathrm{em}=587 \mathrm{~nm}$ ). Cholesterol esterase was used to hydrolyze cholesterol esters in order to measure cholesterol esters and total cholesterol in samples tested.

\section{Cell culture and small interfering RNA (siRNA) transfection}

Human hepatocellular carcinoma cell line HepG2 was obtained from ATCC (ATCC; Manassas, VA). Cells were maintained in standard Minimum Essential Eagle's Medium (MEM; Sigma) with the addition of $2 \mathrm{mM}$ glutamine, $1 \%$ non-essential amino acids, $10 \%$ fetal bovine serum, penicillin (100 IU per $\mathrm{mL})$, and streptomycin $(100 \mu \mathrm{g}$ per $\mathrm{mL})$. Prior to small interfering RNA (siRNA) transfection, cells were passaged in 6-well plates at $10^{5}$ cells per well and cultured at $37{ }^{\circ} \mathrm{C}$ and grown to approximately $70 \%$ confluence. Two different sequences of siRNA targeting HNF1 $\alpha$ were used: (a) Hs-TCF1-2, No SI00011620, and (b) Hs-TCF1-5, No SI03095015. AllStars Negative Control, No 1027280 was used as negative control (siRNA NC). All siRNAs were obtained from Qiagen (Crawley, UK). HepG2 cells treated by lipofectamine were used as controls (CON). HepG2 cells were transfected with siRNA at concentrations of $10 \mathrm{nM}$, using $0.1 \%(\mathrm{v} / \mathrm{v})$ Lipofectamine RNAiMAX (Invitrogen, Paisley, UK), as described in the manufacturer's protocol. Transfection reactions were performed in serum-free OptiMEM (Invitrogen, Paisley, UK). Cells were harvested after $48 \mathrm{~h}$ and used for total RNA isolation.

\section{RNA isolation and mRNA level determination}

Total cellular RNA was isolated from the frozen liver samples and HepG2 cell pellets with a commercial RNA isolation kit (Total RNA Mini, A\&A biotechnology, Poland). RNA concentration was determined on the basis of absorbance at $260 \mathrm{~nm}$; all the samples showed 260/280 nm absorbance ratio of about 2.0. Prior to the reverse transcription, the RNA samples were treated with RNase-free DNase I (Fermentas, International Inc., Canada). First strand cDNA synthesis and the determination of mRNA levels by RTPCR were performed as described previously [41], using a CFX Real-Time Detection System (Bio-Rad Laboratories Inc., USA). The primer sequences used in this study are presented in Table 1. $\beta$-actin mRNA was used as an internal
Table 1 The sequences of primers used in this study

\begin{tabular}{ll}
\hline Gene & Primer sequence $\left(5^{\prime}-3^{\prime}\right)$ \\
\hline$H N F 1 \alpha$ & F: AAGATGACACGGATGACGATGG \\
& R: GGTTGAGACCCGTAGTGTCC \\
FNF4 $\alpha$ & F: AAATGTGCAGGTGTTGACCA \\
& R: CACGCTCCTCCTGAAGAATC \\
PCSK9 & F: TGGCTGCATGACATTGCTTCTC \\
& R: GCACTGGAGAACCACACAGG \\
& F: GAAATCGTGCGTGACATTAAG \\
& R: GCTAGAAGCATTTGCGGTGGA \\
\hline
\end{tabular}

standard. Relative quantities of the transcripts were calculated using the $2^{-\Delta \Delta C T}$ formula [42]. The amplification of specific transcripts was further confirmed on the basis of the melting curve profiles.

\section{SDS-PAGE and immunoblotting}

Frozen rat liver was homogenized in $20 \mathrm{mM}$ Tris- $\mathrm{HCl}$ buffer ( $\mathrm{pH} 7.8$ ) containing $0.2 \%$ Triton $\mathrm{X}-100$ and protease inhibitor cocktail (Sigma, USA), and then centrifuged (15 $000 \times$ $g, 20 \mathrm{~min}, 20^{\circ} \mathrm{C}$ ). Aliquots of the obtained supernatants containing $10 \mu \mathrm{g}$ of protein were separated by $10 \%$ SDS-PAGE and electroblotted to Immuno-Blot ${ }^{\mathrm{TM}}$ PVDF Membrane (Bio-Rad Laboratories, Hercules CA, USA). The membrane was blocked by incubation with blocking buffer, and then incubated with rabbit polyclonal anti- HNF4 $\alpha$ antibody (NBP1-00876, Novusbio), mouse monoclonal anti-HNF1 $\alpha$ antibody (GTX12064, GeneTex), rabbit polyclonal antiLDL-Receptor antibody (AB30532, ABCAM), goat polyclonal anti-PCSK9 (AF3985-SP, R\&D Systems), and rabbit polyclonal anti-actin antibody (A 5060, Sigma-Aldrich). Secondary HRP-conjugated antibodies were obtained from Sigma Aldrich (A0545, A9044, A5420). The reactions were visualized with a SuperSignal West Pico chemiluminescent substrate (Thermo Fisher Scientific Inc., Rockford, IL, USA). The bands (visible on the film after the chemiluminescent detection) were compared to molecular mass protein markers (SM1811) obtained from Fermentas, visible on the membrane after electroblotting. The film was adjusted to the membrane in such way that the membrane edges were visible on the film. Blots were analyzed using Quantity One program, version 4,0 (Bio-Rad).

\section{Statistical analysis}

Statistical analysis was conducted using a MS Excel 2010 spreadsheet (Microsoft). All the data were expressed as mean values $( \pm S D)$ for the controls and lipectomized rats. The significance of differences was analyzed with Student 
$t$-test. The differences were considered significant at $p$ value $<0.05$.

\section{Results}

The effects of lipectomy on the mass of inguinal, retroperitoneal and epididymal WAT were previously reported [41]. Briefly, lipectomy resulted in a complete reduction of inguinal adipose tissue and approximately $80 \%$ reduction of retroperitoneal and epididymal adipose tissue as compared to the control rats. Consequently, the overall reduction of sum inguinal, retroperitoneal, and epididymal adipose tissue mass in the lipectomized rats corresponded to approximately $90 \%$. However, one has to keep in mind that other anatomical WAT sites like mesenteric, gluteal, perirenal, and interscapular, whose corresponds to approximately $75-80 \%$ of total adipose tissue in rats [43], has not been dissected (except of mesenteric WAT). Mean baseline body weights of the controls and lipectomized rats were essentially simi$\operatorname{lar}(312 \pm 18 \mathrm{~g}$ vs. $315 \pm 19 \mathrm{~g})$. Mean final body weights determined at the end of the experiment were $403 \pm 21 \mathrm{~g}$ and $407 \pm 17 \mathrm{~g}$ for the controls and lipectomized rats, respectively. Similar final body weight for the controls and lipectomized rats, suggested that partial lipectomy induces a compensatory increase of adipose tissue mass located in different anatomical sites, including visceral fat. Previously, we have observed significant increase of mesenteric WAT mass after lipectomy as compared to control rats [44]. It should be noted that in normal weight women abdominal liposuction also induces increase of visceral fat [45].

Partial lipectomy was reflected by an increase in the serum concentration of total cholesterol (Fig. 1a), and VLDL-cholesterol + LDL- cholesterol (Fig. 1b). Simultaneously, slight but statistically significant decrease in serum HDL-cholesterol concentration in lipectomized rats
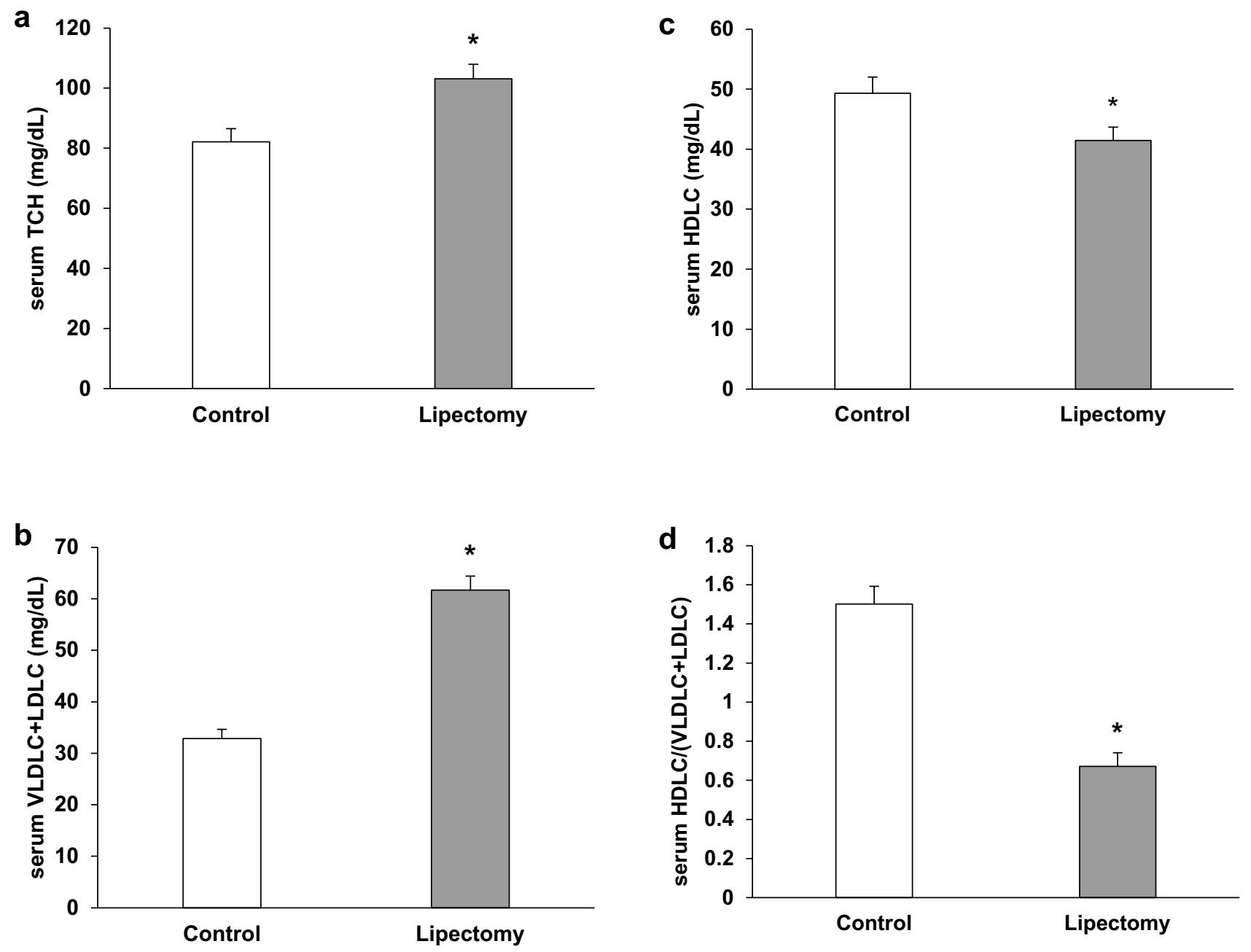

Fig. 1 Serum cholesterol concentrations: a total serum cholesterol (TCH); b VLDL + LDL-cholesterol; c HDL-cholesterol and d serum HDLC/ $\left(\right.$ VLDLC + LDLC) ratio of the controls and lipectomized rats. $a . u$. arbitrary units. Data are presented as mean \pm SD. ${ }^{*} p<0.05$ 
was found (Fig. 1c). Subsequently serum HDL-cholesterol/ VLDL-Cholesterol + LDL_Cholesterol ratio significantly decreased in lipectomized rats as compared to control animals (Fig. 1d). The increase of serum total cholesterol and VLDL-cholesterol + LDL- cholesterol concentrations was associated with an increase in the liver tissue of: (a) total cholesterol (Fig. 2a, b) free cholesterol (Fig. 2b, c) cholesterol esters (Fig. 2c) content. Moreover there was a strong negative correlation between the increase of total serum cholesterol and weight of total fat that resembled after two surgeries $(\mathrm{r}=-0.79 ; p<0.05)$.

Changes in serum and liver cholesterol concentration after partial lipectomy were associated with significant decrease in the liver LDL-receptor (LDL-R) determined by Western blot (Fig. 3). The decrease in liver LDL-R was associated with higher level of PCSK9 mRNA in liver of lipectomized rats (Fig. 4a). Different liver expression levels of PCSK9 mRNA observed in the controls and lipectomized rats were reflected by intergroup differences in the liver levels of PCSK9 protein documented on Western Blot analysis (Fig. 4b) and serum PCSK9 concentrations (Fig. 4c). Thus, it is very likely that enhanced expression of gene encoding liver PCSK9 leads to higher serum PCSK9 concentration (Fig. 4d) and contributes to the decrease in the liver LDL-R (Fig. 3). In turn, these changes probably contribute to the increase in serum total and VLDL + LDL-cholesterol concentrations (Fig. 2). This assumption was supported by: (a) very strong negative correlation found between the serum PCSK9 concentration and the liver LDL-R level $(r=-0.92$; $p<0.05)$ and (b) very strong positive correlation between serum VLDL-cholesterol + LDL-cholesterol and serum PCSK9 level $(r=0.95 ; p<0.05)$.

As expected, partial lipectomy was reflected by approximately three-fold increase in the liver HNF1 $\alpha$ (Fig. 5a) and about five-fold increase in HNF4 $\alpha$ (Fig. 5b) mRNA levels. The different liver levels of HNF1 $\alpha$ and HNF $4 \alpha$ mRNA of the controls and lipectomized rats were reflected by intergroup differences in the HNF $1 \alpha$ and HNF $4 \alpha$ protein levels documented on Western Blot analysis (Fig. 5c-representative western blots and Fig. 5d, e-densitometric analysis of Western Blots bands).

The pattern of changes in the liver HNFs mRNA and protein levels of the controls and lipectomized rats resembled the one observed in PCSK9 mRNA and protein levels (Figs. 4, 5, respectively). Moreover, strong positive correlations were found between the liver levels of PCSK9 and HNF $1 \alpha$ mRNA $(r=0.82, p<0.05)$. Thus one can suppose that up-regulation of HNF1 $\alpha$ and HNF $4 \alpha$ plays a key role in the increase of PCSK9 gene expression in lipectomized rats. To confirm this assumption HNF1 $\alpha$ deregulation was performed and its effect on PCSK9 gene expression in hepatocyte cells (HepG2) was examined. As shown in Fig. 6 the decrease in HNF1 $\alpha$ mRNA levels by two different siRNA
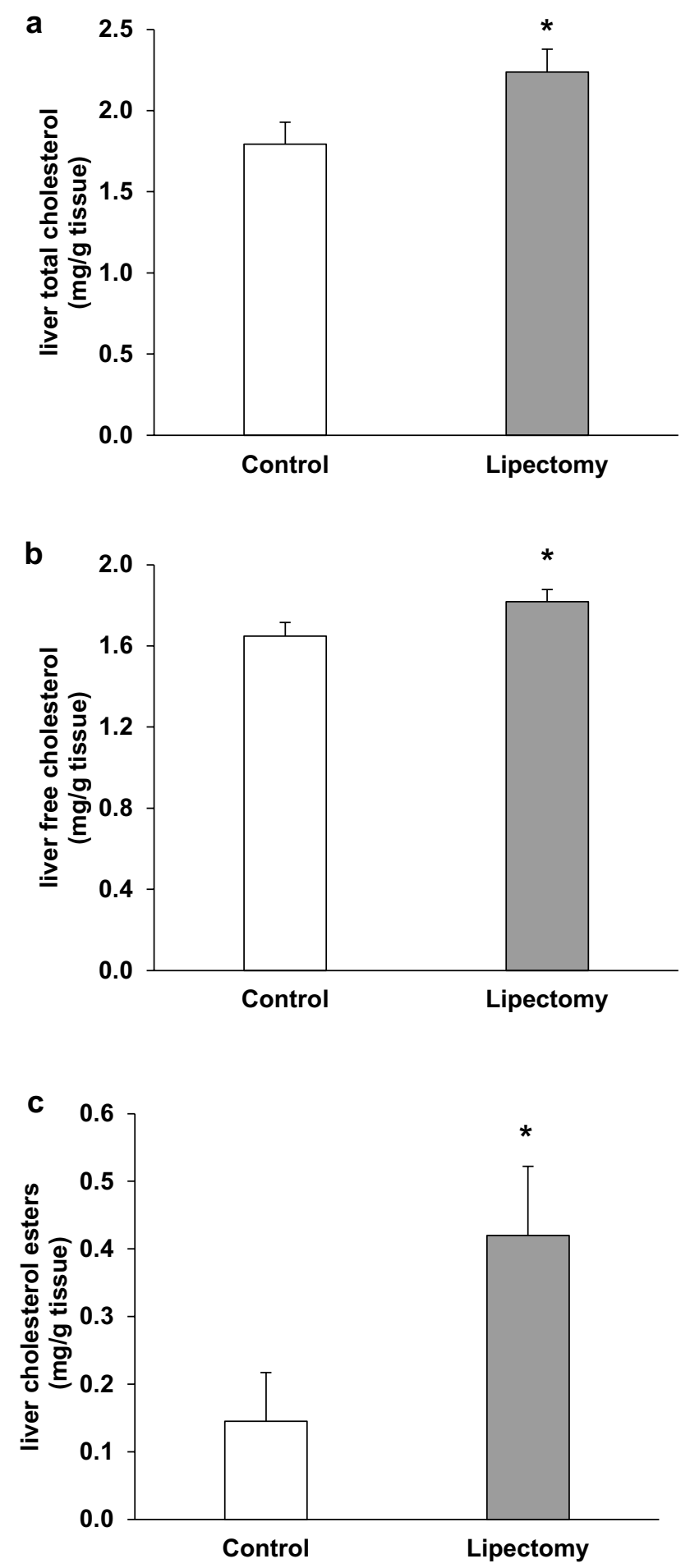

Fig. 2 Liver cholesterol concentrations: a total liver cholesterol; b free cholesterol; c cholesterol esters of the controls and lipectomized rats. a.u. arbitrary units. Data are presented as mean \pm SD. $* p<0.05$

(TCF 1-2 and TCF 1-5) was associated with the decrease in PCSK9 mRNA level. Together, the results presented above, especially parallel expression of PCSK9 and HNF1 $\alpha$ both in vivo and in vitro, suggest that up-regulation of HNF $1 \alpha$ 

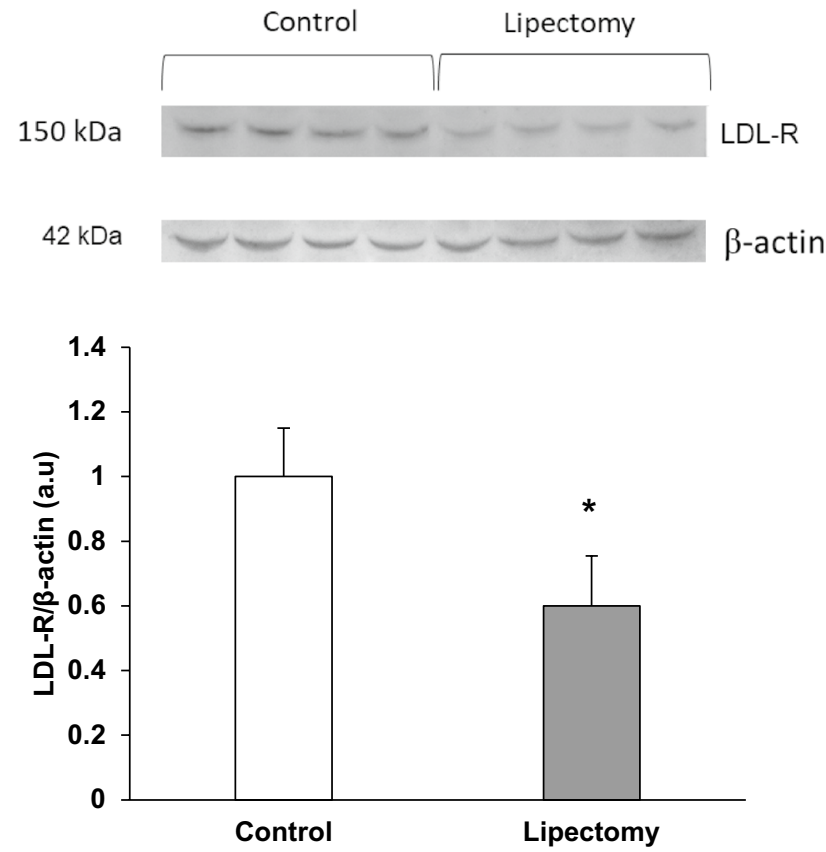

Fig. 3 Western blot analysis of liver LDL-R: upper panel-representative western blot analysis of the controls and lipectomized rats; lower panel-densitometric analysis of western blot bands standardized against actin. a.u. arbitrary units. Data are presented as mean \pm SD. ${ }^{*} p<0.05$

contributes to the increase in liver PCSK9 gene expression and leads to hypercholesterolemia in lipectomized rats.

\section{Discussion}

This study was the first to show that reduction of fat mass induced by the surgical removal of total inguinal and majority of retroperitoneal and epididymal adipose tissue in rats may be associated with up-regulation of gene encoding liver PCSK9 and subsequently with higher level of PCSK9 in serum. This in turn may lead to decrease in liver LDL-R and elevated serum cholesterol concentration. PCSK9 is a serine protease synthesized and released mainly by liver, which binds to LDL-R on the surface of hepatocyte, forming a complex that is internalized and degraded [46]. By promoting degradation of LDL-R, PCSK9 prevents its recycling to the hepatocyte membrane, leading to a substantial reduction of LDL-R level [47]. As shown in this paper, the increase in expression of gene encoding PCSK9 and increase in serum PCSK9 concentration (Fig. 4) were associated with the decrease in LDL-R level (Fig. 3) and increase in the serum and liver cholesterol concentrations (Figs. 1,2). This suggests that the up-regulation of gene encoding PCSK9 in liver and subsequently elevated serum PCSK9 concentration may contribute to the decrease in liver LDL-R after lipectomy.
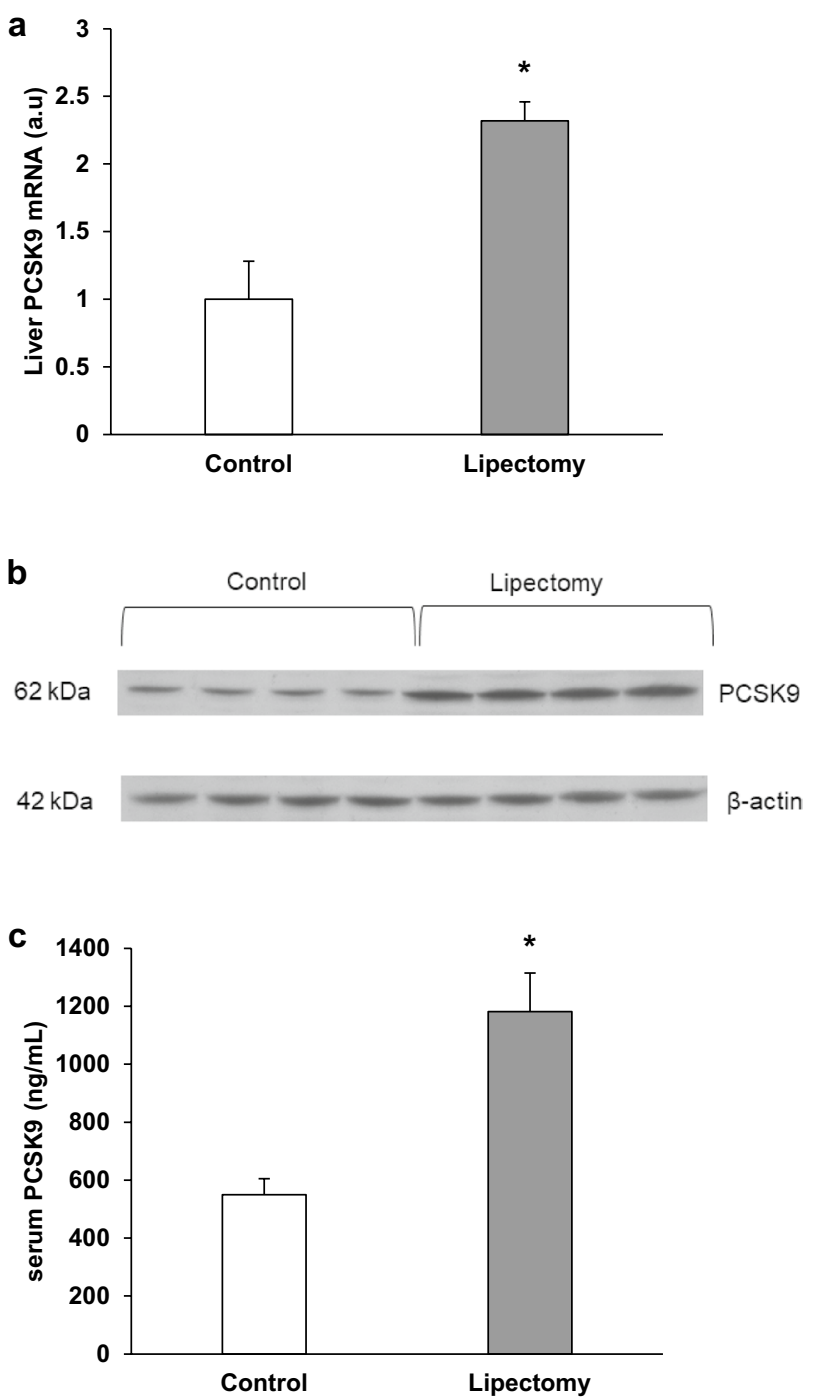

Fig. 4 Analysis of PCSK9: a liver mRNA relative levels; $\mathbf{b}$ representative liver western blot protein analysis standardized against actin and c serum PCSK9 concentrations of controls and lipectomized rats. a.u. arbitrary units. Data are presented as mean \pm SD. ${ }^{*} p<0.05$

Therefore, the changes in serum PCSK9 concentration and the decrease in liver LDL-R may contribute to the increase in the serum concentration of cholesterol after lipectomy. PCSK9 is expressed in other organs including lungs [48]. Thus, it is not excluded that production of PCSK9 by lungs contributes also to the increase in serum concentration of this protein. However, the effect of lipectomy on regulation of lung PCSK9 expression requires further studies.

Taking into account the results of previous studies in which HNF1 $\alpha$ and HNF4 $\alpha$ were shown to be transcriptional activators of gene encoding PCSK9 in liver [23, 25, 49], and our hereby presented findings, we hypothesize that these hepatocyte nuclear factors through transcriptional up-regulation of gene encoding PCSK9 might contribute 

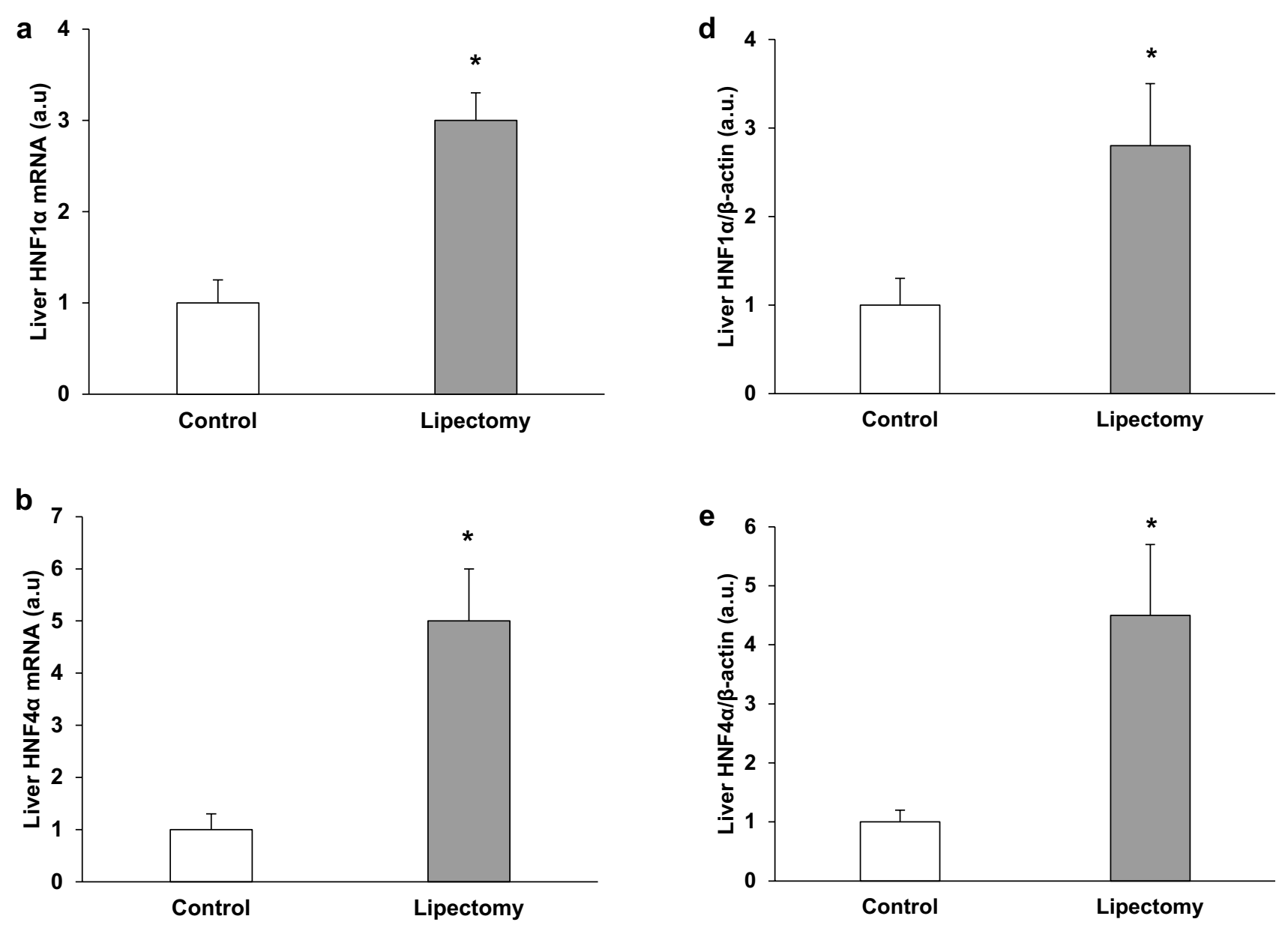

C

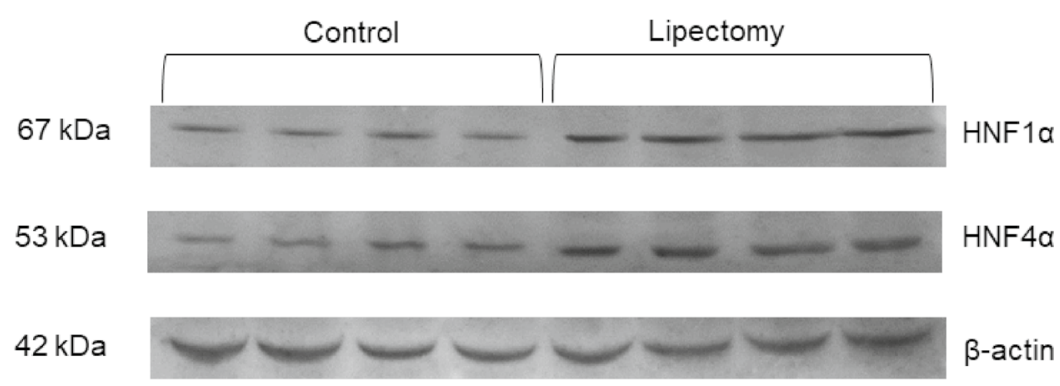

Fig. 5 Analysis of HNF transcription factors in liver: a HNF1 $\alpha$ mRNA relative levels; b HNF $4 \alpha$ mRNA relative levels c representative western blot protein analysis of HNF1 $\alpha$ and HNF4 $\alpha$ standardized against actin of controls and lipectomized rats, $\mathbf{d}$ densitometric analy-

to the hypercholesterolemia observed in lipectomized rats. The hypothesis is based on: (a) the fact that gene encoding PCSK9 is a target of HNFs [23, 25, 49], (b) strong positive correlation between $h n f l \alpha$ and pcsk 9 expression found in liver, (c) strong negative correlation between HNFs and LDL-R protein levels determined by western blot, and (d) strong negative correlation between serum PCSK9 concentration and liver LDL-R level. sis of western blot HNF1 $\alpha$ bands standardized against actin, e densitometric analysis of western blot $\mathrm{HNF} 4 \alpha$ bands standardized against actin. $a . u$. arbitrary units. Data are presented as mean \pm SD. $* p<0.05$

Pivotal role of HNFs (especially HNF4 $\alpha$ ) in maintaining cholesterol homeostasis comes also from the experimental data obtained with liver $H n f 4 \alpha^{-1-}$ mice. For instance, serum cholesterol concentrations were shown to be significantly reduced in liver specific $H n f 4 \alpha^{-1-}$ mice [20]. Similarly, acute loss of liver $H n f 4 \alpha$ in mice, generated by adenovirus expressing small hairpin RNA corresponding to $H n f 4 \alpha$, leads to hypocholesterolemia [21]. These results suggest that 

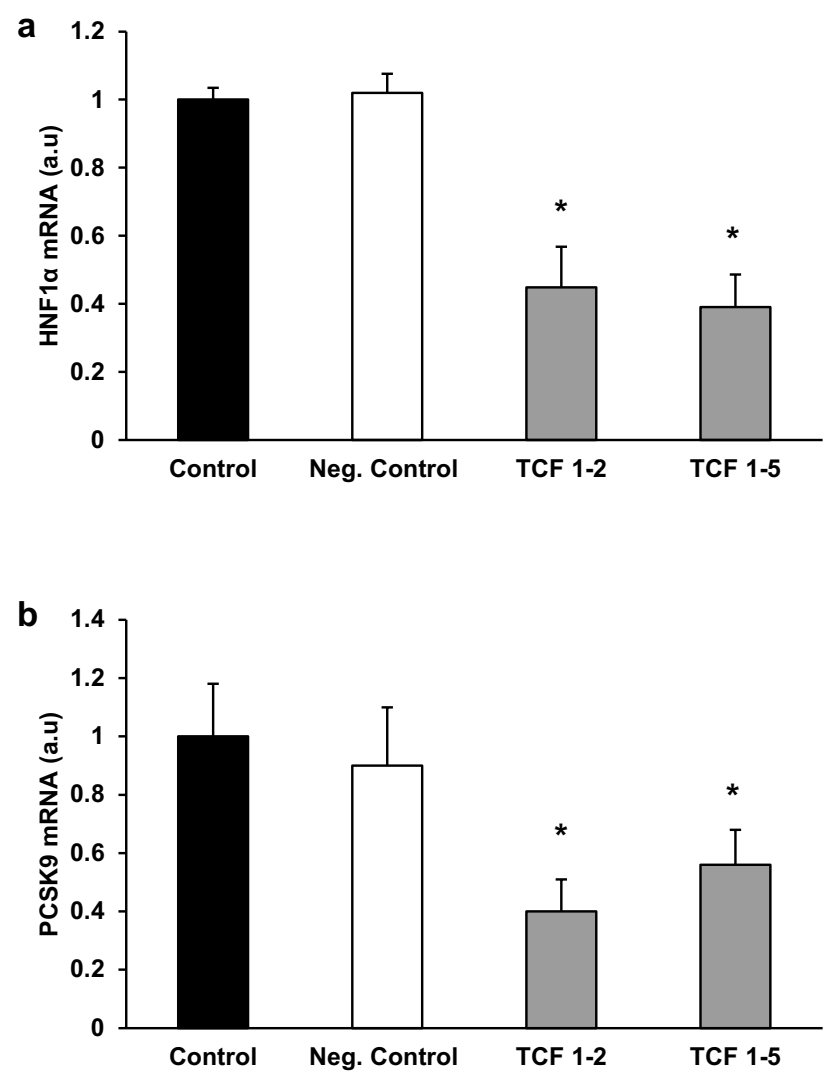

Fig. 6 Subsequent inhibition of HNF1 $\alpha$ and PCSK9 expression in HepG 2 cells. silencing of HNF1 $\alpha$ expression by two different siRNA (a) resulted in decrease of PSCK9 mRNA expression (b). Lipofectamine-treated cells were used as control. Graphs represent the mean \pm SD of data from 6 cell plates in three separate experiments. a.u. arbitrary units. ${ }^{*} p<0.05$

liver $H n f 4 \alpha$ plays an important role in regulation of serum cholesterol concentrations. Yin et al. [21] suggests that the decrease in serum cholesterol concentration in mice after acute loss of liver $H n f 4 \alpha$ is caused by inhibition of: (a) de novo cholesterol biosynthesis, (b) VLDL secretion, and (c) HDL formation. The results presented here indicate that HNFs may affect serum cholesterol concentration via regulation of serum PCSK9 level and consequently LDL-R level in hepatocytes. It means that up-regulation of liver HNFs in lipectomized rats may lead to increase of serum cholesterol concentration through decrease in LDL-R and increase in cholesterol synthesis.

In addition to its role in degradation of LDL-R, PCSK9 promotes degradation of VLDL-R [50] and fatty acid translocase (also known as CD36), what contributes to decrease in VLDL and long chain fatty acid [51] uptake. Thus, high level of serum PCSK9, promoting VLDL-R and CD36 degradation, could also contribute to elevated serum VLDL-cholesterol and FFA level (Fig. 1b) leading to hypertriglyceridemia found in lipectomized rats $[17,18]$.
As already mentioned in the "Introduction" section, upregulation of gene encoding HNF4 $\alpha$ was also observed in lipectomized obese rats [17]. Given the pivotal role of HNFs in up-regulation of gene encoding PCSK9, one would expect elevated concentration of serum PCSK9 and cholesterol. Surprisingly, lipectomy performed in this experimental model has no significant effect on serum concentration of total, LDL- and HDL-cholesterol [17]. Since serum PCSK9 concentrations (as well as pcsk 9 regulation) has not been presented by Ling and co-workers [17], the reasons for the discrepancy between results presented here and Ling and co-workers [17] is unknown. We can speculate that different diets used in our experiments (normal laboratory diet) and in Ling and co-workers experiments (high fat and cholesterol diet) could be the reason.

Besides parallel up-regulation of genes encoding liver HNFs and PCSK9, the role of HNFs in regulation of gene encoding PCSK9 was confirmed by the results presented in Fig. 6, which shows that silencing of HNF1 $\alpha$ with small interfering RNA (siRNA) led to the decrease in in PCSK9 mRNA levels in HepG2 cells. However, the reasons behind the increased expressions of Hnfl $\alpha$ and $H n f 4 \alpha$ in the rat liver after surgical removal of adipose tissue are still unclear. The expression of gene encoding Hnf $4 \alpha$ was postulated to be down-regulated by cytokines including IL- $1 \beta$ [52, 53], and removal of adipose tissue was shown to be reflected by a decrease in the circulating levels of pro-inflammatory cytokines [54, 55]. Thus, it can be hypothesized that surgical removal of adipose tissue in rats may result in a decrease in cytokine levels, which in turn leads to increase in the expression of $H n f 4 \alpha$ gene.

In view of the pivotal role of HNF $1 \alpha$ and HNF $4 \alpha$ in the lipid metabolism and maintenance of serum cholesterol concentration in lipectomized rats, one may ask how these findings translate onto humans subjected to liposuction (or humans with lipodystrophy). At present we can only hypothesize that similar to the lipectomized rats, patients after liposuction may present with: (a) increased liver levels of HNF $1 \alpha, H N F 4 \alpha$, and PCSK9; (b) increased circulating PCSK9 concentration; and (c) decreased liver level of LDL-R and resultant increase of serum cholesterol concentration. In fact, Ybarra et al. [12] showed that liposuction removal of subcutaneous abdominal fat in normaloverweight subjects results in an increase in circulating (a) total cholesterol; (b) LDL-cholesterol; and (c) ApoB-100 and LDL-cholesterol/ ApoB-100 ratio. This observation is in line with our hereby presented findings. Moreover, elevated concentrations of serum total and LDL-cholesterol concentrations were also found in some patients with lipodystrophy $[13,14]$. However, in the most studies reported so far, abdominal liposuction did not have significant effect on circulating cholesterol concentration [3-7] or even decrease in the serum cholesterol concentrations 


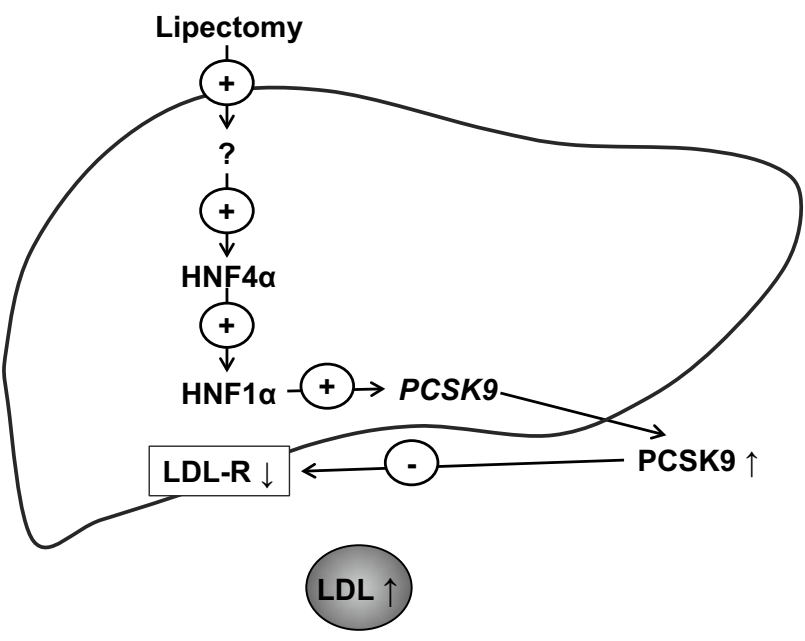

Fig. 7 Proposed mechanism showing how HNFs may affect circulating LDL-cholesterol concentration in rats after lipectomy. Lipectomy causes increase of liver HNF $4 \alpha$ and HNF $1 \alpha$. HNF $1 \alpha$ activates Pcsk 9 gene promoter leading to increased concentration of plasma PCSK9. PCSK9 binds to LDL-R and impairs proper scavenging of serum LDL-cholesterol. For details see "Discussion"

of was found [8-11]. Moreover, no changes in serum total and LDL-cholesterol concentrations in some patients with lipodystrophy were also observed $[15,56]$. Thus, at present it would be inappropriate to speculate if the changes taking place in humans subjected to liposuction are similar to those observed in our partially lipectomized rats.

In conclusion, our study showed that partial surgical removal of WAT in rats is associated with the coordinated up-regulation of liver genes encoding $\operatorname{Hnf} 1 \alpha, \operatorname{Hnf} 4 \alpha$ and PCSK9. These changes are associated with increased circulating PCSK9 concentration, and decrease in liver LDLR. Consequently, the post-lipectomy increase in circulating cholesterol concentration may result from decreased uptake of cholesterol by LDL-R in rat liver. The above mentioned mechanism of post-lipectomy hypercholesterolemia is summarized on Fig. 7. Although our findings provide a new insight into post-lipectomy catabolism of cholesterol in experimental model, further studies are needed to determine an association between hypercholesterolemia, circulating PCSK9 concentrations and up-regulation of genes encoding PCSK9, HNF1 $\alpha$, and HNF $4 \alpha$ in humans subjected to liposuction or patients with lipodystrophy.

Acknowledgements We are indebted to Prof. Julian Swierczynski for criticism and discussion of the manuscript. The study was supported from the Medical University of Gdansk Grants No. ST-41 and ST-40.

\section{Compliance with ethical standards}

Conflict of interest The authors declare that they have no conflict of interest.
Open Access This article is distributed under the terms of the Creative Commons Attribution 4.0 International License (http://creativeco mmons.org/licenses/by/4.0/), which permits unrestricted use, distribution, and reproduction in any medium, provided you give appropriate credit to the original author(s) and the source, provide a link to the Creative Commons license, and indicate if changes were made.

\section{References}

1. American Academy of Cosmetic Surgery (AACS) (2006) Guidelines for Liposuction Surgery. In: 2006: a joint Ad Hoc Committee of the American Society of Lipo-Suction Surgery (ASLSS) and the American Academy of Cosmetic Surgery 2006

2. Seretis K, Goulis DG, Koliakos G, Demiri E (2015) Short- and long-term effects of abdominal lipectomy on weight and fat mass in females: a systematic review. Obes Surg 25:1950-1958

3. Klein S, Fontana L, Young VL, Coggan AR, Kilo C, Patterson BW, Mohammed BS (2004) Absence of an effect of liposuction on insulin action and risk factors for coronary heart disease. $\mathrm{N}$ Engl J Med 350:2549-2557

4. Martínez-Abundis E, Molina-Villa CA, González-Ortiz M, Robles-Cervantes JA, Saucedo-Ortiz JA (2007) Effect of surgically removing subcutaneous fat by abdominoplasty on leptin concentrations and insulin sensitivity. Ann Plast Surg 58:416-419

5. Mohammed BS, Cohen S, Reeds D, Young VL, Klein S (2008) Long-term effects of large-volume liposuction on metabolic risk factors for coronary heart disease. Obesity (Silver Spring) 16:2648-2651

6. Busetto L, Bassetto F, Zocchi M, Zuliani F, Nolli ML, Pigozzo S, Coin A, Mazza M, Sergi G, Mazzoleni F, Enzi G (2008) The effects of the surgical removal of subcutaneous adipose tissue on energy expenditure and adipocytokine concentrations in obese women. Nutr Metab Cardiovasc Dis 18:112-120

7. Fabbrini E, Tamboli RA, Magkos F, Marks-Shulman PA, Eckhauser AW, Richards WO, Klein S, Abumrad NN (2010) Surgical removal of omental fat does not improve insulin sensitivity and cardiovascular risk factors in obese adults. Gastroenterology 139:448-455

8. D'Andrea F, Grella R, Rizzo MR, Grella E, Grella R, Nicoletti G, Barbieri M, Paolisso G (2005) Changing the metabolic profile by large-volume liposuction: a clinical study conducted with 123 obese women. Aesthetic Plast Surg 29:472-478

9. Davis DA, Pellowski DM, Davis DA, Donahoo WT (2006) Acute and 1-month effect of small-volume suction lipectomy on insulin sensitivity and cardiovascular risk. Int J Obes (Lond) 30:1217-1222

10. Giese SY, Bulan EJ, Commons GW, Spear SL, Yanovski JA (2001) Improvements in cardiovascular risk profile with large-volume liposuction: a pilot study. Plast Reconstr Surg 108:510-519

11. Robles-Cervantes JA, Yánez-Díaz S, Cárdenas-Camarena L (2004) Modification of insulin, glucose and cholesterol levels in nonobese women undergoing liposuction: is liposuction metabolically safe? Ann Plast Surg 52:64-67

12. Ybarra J, Blanco-Vaca F, Fernández S, Castellví A, Bonet R, Palomer X, Ordóñez-Llanos J, Trius A, Vila-Rovira R, Pérez A (2008) The effects of liposuction removal of subcutaneous abdominal fat on lipid metabolism are independent of insulin sensitivity in normal-overweight individuals. Obes Surg 18:408-414

13. Faria CA, Moraes RS, Sobral-Filho DC, Rego AG, Baracho MF, Egito ES, Brandão-Neto J (2009) Autonomic modulation in patients with congenital generalized lipodystrophy (BerardinelliSeip syndrome). Europace 11:763-769

14. Francis GA, Li G, Casey R, Wang J, Cao H, Leff T, Hegele RA (2006) Peroxisomal proliferator activated receptor-gamma 
deficiency in a Canadian kindred with familial partial lipodystrophy type 3 (FPLD3). BMC Med Genet 7:3

15. Rubio-Cabezas O, Puri V, Murano I, Saudek V, Semple RK, Dash S, Hyden CS, Bottomley W, Vigouroux C, Magré J, Raymond-Barker P, Murgatroyd PR, Chawla A, Skepper JN, Chatterjee VK, Suliman S, Patch AM, Agarwal AK, Garg A, Barroso I, Cinti S, Czech MP, Argente J, O'Rahilly S, Savage DB, LD Screening Consortium (2009) Partial lipodystrophy and insulin resistant diabetes in a patient with a homozygous nonsense mutation in CIDEC. EMBO Mol Med 1:280-287

16. Cortés VA, Fernández-Galilea M (2015) Lipodystrophies: adipose tissue disorders with severe metabolic implications. J Physiol Biochem 71:471-478

17. Ling BL, Chiu CT, Lu HC, Lin JJ, Kuo CY, Chou FP (2014) Short and long-term impact of lipectomy on expression profile of hepatic anabolic genes in rats: a high fat and high cholesterol diet-induced obese model. PLoS ONE 9:e108717

18. Dettlaff-Pokora A, Sledzinski T, Swierczynski J (2015) Upregulation Mttp and Apob gene expression in rat liver is related to post-lipectomy hypertriglyceridemia. Cell Physiol Biochem 36:1767-1777

19. Packard CJ, Demant T, Stewart JP, Bedford D, Caslake MJ, Schwertfeger G, Bedynek A, Shepherd J, Seidel D (2000) Apolipoprotein B metabolism and the distribution of VLDL and LDL subfractions. J Lipid Res 41:305-318

20. Hayhurst GP, Lee YH, Lambert G, Ward JM, Gonzalez FJ (2001) Hepatocyte nuclear factor 4alpha (nuclear receptor 2A1) is essential for maintenance of hepatic gene expression and lipid homeostasis. Mol Cell Biol 21:1393-1403

21. Yin L, Ma H, Ge X, Edwards PA, Zhang Y (2011) Hepatic hepatocyte nuclear factor $4 \alpha$ is essential for maintaining triglyceride and cholesterol homeostasis. Arterioscler Thromb Vasc Biol 31:328-336

22. Li H, Dong B, Park SW, Lee HS, Chen W, Liu J (2009) Hepatocyte nuclear factor 1alpha plays a critical role in PCSK9 gene transcription and regulation by the natural hypocholesterolemic compound berberine. J Biol Chem 284:28885-28895

23. Shende VR, Wu M, Singh AB, Dong B, Kan CF, Liu J (2015) Reduction of circulating PCSK9 and LDL-C levels by liverspecific knockdown of HNF1 $\alpha$ in normolipidemic mice. J Lipid Res 56:801-809

24. Xu RX, Liu J, Li XL, Li S, Zhang Y, Jia YJ, Sun J, Li JJ (2015) Impacts of ezetimibe on PCSK9 in rats: study on the expression in different organs and the potential mechanisms. J Transl Med 13:87

25. Sucajtys-Szulc E, Szolkiewicz M, Swierczynski J, Rutkowski B (2016) Up-regulation of Hnfl $\alpha$ gene expression in the liver of rats with experimentally induced chronic renal failure - A possible link between circulating PCSK9 and triacylglycerol concentrations. Atherosclerosis 248:17-26

26. Sucajtys-Szulc E, Szolkiewicz M, Swierczynski J, Rutkowski B (2016) Up-regulation of liver Pcsk9 gene expression as a possible cause of hypercholesterolemia in experimental chronic renal failure. Mol Cell Biochem 411:281-287

27. Schulz R, Schlüter KD, Laufs U (2015) Molecular and cellular function of the proprotein convertase subtilisin/kexin type 9 (PCSK9). Basic Res Cardiol 110:4

28. Lakoski SG, Lagace TA, Cohen JC, Horton JD, Hobbs HH (2009) Genetic and metabolic determinants of plasma PCSK9 levels. J Clin Endocrinol Metab 94:2537-2543

29. Dubuc G, Tremblay M, Paré G, Jacques H, Hamelin J, Benjannet S, Boulet L, Genest J, Bernier L, Seidah NG, Davignon J (2010) A new method for measurement of total plasma PCSK9: clinical applications. J Lipid Res 51:140-149

30. Alborn WE, Cao G, Careskey HE, Qian YW, Subramaniam DR, Davies J, Conner EM, Konrad RJ (2007) Serum proprotein convertase subtilisin kexin type 9 is correlated directly with serum LDL cholesterol. Clin Chem 53:1814-1819

31. Lambert G, Ancellin N, Charlton F, Comas D, Pilot J, Keech A, Patel S, Sullivan DR, Cohn JS, Rye KA, Barter PJ (2008) Plasma PCSK9 concentrations correlate with LDL and total cholesterol in diabetic patients and are decreased by fenofibrate treatment. Clin Chem 54:1038-1045

32. Lehto M, Bitzén PO, Isomaa B, Wipemo C, Wessman Y, Forsblom C, Tuomi T, Taskinen MR, Groop L (1999) Mutation in the HNF4alpha gene affects insulin secretion and triglyceride metabolism. Diabetes 48:423-425

33. Shih DQ, Dansky HM, Fleisher M, Assmann G, Fajans SS, Stoffel M (2000) Genotype/phenotype relationships in HNF-4alpha/ MODY1: haploinsufficiency is associated with reduced apolipoprotein (AII), apolipoprotein (CIII), lipoprotein(a), and triglyceride levels. Diabetes 49:832-837

34. Pramfalk C, Karlsson E, Groop L, Rudel LL, Angelin B, Eriksson M, Parini P (2009) Control of ACAT2 liver expression by HNF4\{alpha\}: lesson from MODY1 patients. Arterioscler Thromb Vasc Biol 29:1235-1241

35. Xu Y, Zalzala M, Xu J, Li Y, Yin L, Zhang Y (2015) A metabolic stress-inducible miR-34a-HNF4 $\alpha$ pathway regulates lipid and lipoprotein metabolism. Nat Commun 6:7466

36. Yamagata K, Furuta H, Oda N, Kaisaki PJ, Menzel S, Cox NJ, Fajans SS, Signorini S, Stoffel M, Bell GI (1996) Mutations in the hepatocyte nuclear factor-4alpha gene in maturity-onset diabetes of the young (MODY1). Nature 384:458-460

37. Sladek FM, Zhong WM, Lai E, Darnell JE Jr (1990) Liverenriched transcription factor HNF-4 is a novel member of the steroid hormone receptor superfamily. Genes Dev 4:2353-2365

38. Kuo CJ, Conley PB, Chen L, Sladek FM, Darnell JE Jr, Crabtree GR (1992) A transcriptional hierarchy involved in mammalian cell-type specification. Nature 355:457-461

39. Ryffel GU (2001) Mutations in the human genes encoding the transcription factors of the hepatocyte nuclear factor (HNF) 1 and HNF4 families: functional and pathological consequences. J Mol Endocrinol 27:11-29

40. Zhong W, Mirkovitch J, Darnell JE Jr (1994) Tissue-specific regulation of mouse hepatocyte nuclear factor 4 expression. Mol Cell Biol 14:7276-7284

41. Dettlaff-Pokora A, Sledzinski T, Swierczynski J (2015) Up-regulation of orexigenic and down-regulation of anorexigenic neuropeptide gene expression in rat hypothalamus after partial lipectomy. $\mathrm{J}$ Appl Biomed 13:105-112

42. Livak KJ, Schmittgen TD (2001) Analysis of relative gene expression data using real-time quantitative PCR and the 2(-Delta Delta $\mathrm{C}(\mathrm{T})$ ) method. Methods 25:402-408

43. Remesar X, Fernández-López JA, Blay MT, Savall P, Salas A, Díaz-Silva M, Esteve M, Grasa MM, Alemany M (2002) Effect of oral oleoyl-estrone on adipose tissue composition in male rats. Int J Obes Relat Metab Disord 26:1092-1102

44. Dettlaff-Pokora A, Sledzinski T, Swierczynski J (2016) Upregulation of Pnpla2 and Abhd5 and downregulation of G0s2 gene expression in mesenteric white adipose tissue of partialy lipectomized rats-a possible cause of elevated concentration of circulating NEFA. MolCellBiochem 422:21-29

45. Benatti F, Solis M, Artioli G, Montag E, Painelli V, Saito F, Baptista L, Costa LA, Neves R, Seelaender M, Ferriolli E, Pfrimer K, Lima F, Roschel H, Gualano B, Lancha A Jr (2012) Liposuction induces a compensatory increase of visceral fat which is effectively counteracted by physical activity: a randomized trial. J Clin Endocrinol Metab 97:2388-2395

46. Li J, Tumanut C, Gavigan JA, Huang WJ, Hampton EN, Tumanut R, Suen KF, Trauger JW, Spraggon G, Lesley SA, Liau G, Yowe D, Harris JL (2007) Secreted PCSK9 promotes LDL receptor 
degradation independently of proteolytic activity. Biochem J 406:203-207

47. Maxwell KN, Breslow JL (2004) Adenoviral-mediated expression of Pcsk9 in mice results in a low-density lipoprotein receptor knockout phenotype. Proc Natl Acad Sci USA 101:7100-7105

48. Demidyuk IV, Shubin AV, Gasanov EV, Kurinov AM, Demkin VV, Vinogradova TV, Zinovyeva MV, Sass AV, Zborovskaya IB, Kostrov SV (2013) Alterations in gene expression of proprotein convertases in human lung cancer have a limited number of scenarios. PLoS ONE 8:e55752

49. Tai MH, Chen PK, Chen PY, Wu MJ, Ho CT, Yen JH (2014) Curcumin enhances cell-surface LDLR level and promotes LDL uptake through downregulation of PCSK9 gene expression in HepG2 cells. Mol Nutr Food Res 58:2133-2145

50. Poirier S, Mayer G, Benjannet S, Bergeron E, Marcinkiewicz J, Nassoury N, Mayer H, Nimpf J, Prat A, Seidah NG (2008) The proprotein convertase PCSK9 induces the degradation of low density lipoprotein receptor (LDLR) and its closest family members VLDLR and ApoER2. J Biol Chem 283:2363-2372

51. Demers A, Samami S, Lauzier B, Des Rosiers C, Ngo Sock ET, Ong H, Mayer G (2015) PCSK9 induces CD36 degradation and affects long-chain fatty acid uptake and triglyceride metabolism in adipocytes and in mouse liver. Arterioscler Thromb Vasc Biol 35:2517-2525

52. Simó R, Barbosa-Desongles A, Hernandez C, Selva DM (2012) IL1 $\beta$ down-regulation of sex hormone-binding globulin production by decreasing HNF- $4 \alpha$ via MEK-1/2 and JNK MAPK pathways. Mol Endocrinol 26:1917-1927

53. Babeu JP, Boudreau F (2014) Hepatocyte nuclear factor 4-alpha involvement in liver and intestinal inflammatory networks. World J Gastroenterol 20:22-30

54. Esposito K, Giugliano G, Scuderi N, Giugliano D (2006) Role of adipokines in the obesity-inflammation relationship: the effect of fat removal. Plast Reconstr Surg 118:1048-1057

55. Marfella R, Grella R, Rizzo MR, Barbieri M, Grella R, Ferraraccio F, Cacciapuoti F, Mazzarella G, Ferraro N, D'Andrea F, Paolisso G, Nicoletti G (2009) Role of subcutaneous abdominal fat on cardiac function and proinflammatory cytokines in premenopausal obese women. Ann Plast Surg 63:490-495

56. Montenegro RM Jr, Montenegro AP, Fernandes MI, de Moraes RR, Elias J Jr, Gouveia LM, Muglia VF, Foss MC, Moreira AC, Martinelli CE Jr (2002) Triglyceride-induced diabetes mellitus in congenital generalized lipodystrophy. J Pediatr Endocrinol Metab $15: 441-447$ 